\title{
A Redução da Idade de Responsabilidade Criminal na Perspectiva de Adolescentes
}

\author{
Michelle Ferreira Martins ${ }^{1}$ \\ ${ }^{1}$ Universidade Federal de Uberlândia, MG, Brasil. \\ Maíra Lopes Almeida ${ }^{1}$ \\ ${ }^{1}$ Universidade Federal de Uberlândia, MG, Brasil. \\ Tassiana Machado Quagliatto ${ }^{1}$ \\ ${ }^{1}$ Universidade Federal de Uberlândia, MG, Brasil.
}

\author{
Artur Júlio de Albuquerque Junior ${ }^{1}$ \\ ${ }^{1}$ Universidade Federal de Uberlândia, MG, Brasil. \\ Rita de Cássia Cardoso da Silva Mendes ${ }^{1}$ \\ ${ }^{1}$ Universidade Federal de Uberlândia, MG, Brasil. \\ João Luiz Leitão Paravidini ${ }^{1}$ \\ ${ }^{1}$ Universidade Federal de Uberlândia, MG, Brasil.
}

Resumo: A proposta de emenda à Constituição Federal (PEC) 171/1993 prevê a redução da maioridade penal no Brasil de 18 para 16 anos. Essa proposta foi votada pela Câmara dos Deputados e está, atualmente, no Senado Federal, contando com intenso apoio do atual presidente. Embora haja evidências de que a idade não se relaciona a indicadores de violência, a opinião pública se manifesta favorável à medida. Diante disso, considera-se primordial escutar a fala dos próprios adolescentes sobre essa questão. Este trabalho objetivou investigar a perspectiva de adolescentes sobre a redução da maioridade penal. Participaram 25 adolescentes provenientes de uma escola pública e cinco que estavam em cumprimento de medida socioeducativa, todos na faixa etária entre 12 e 17 anos. A coleta de dados ocorreu por meio de rodas de conversa com o primeiro grupo e entrevistas com o segundo. Foram escritos relatos em ambos os momentos da coleta. Para a análise, esses relatos foram lidos e discutidos em grupo pelos pesquisadores. Os resultados apontam alguns analisadores que emergiram a partir das rodas e entrevistas: adolescência, raiva, medo, questão social, lei e violência. Observou-se que os participantes foram além de um posicionamento opinativo, produzindo importantes elaborações sobre o tema que foram disparadores capazes de abordar problemáticas próprias da adolescência e da realidade social. Considera-se que é tarefa ímpar da psicologia trazer à luz opiniões como as dos adolescentes objeto desta pesquisa.

Palavras-chave: Maioridade Penal, Adolescência, Psicanálise, Roda de Conversa, Entrevistas.

\section{Lowering the Minimum Age of Criminal Responsibility from the Perspective of Adolescents}

\begin{abstract}
The proposed amendment to the Federal Constitution (PEC 171/1993) of Brazil provides for the lowering of the minimum age of criminal responsibility from 18 to 16 years. This proposal was voted by the House of Representatives and is currently in the Federal Senate, being strongly supported by the elected President. Despite evidence showing that age is unrelated to indicators of violence, public opinion supports the measure, indicating the urge for listening to the opinion of adolescents on this subject. This study aimed to investigate the perspective of adolescents regarding the lowering of the minimum age of criminal responsibility in Brazil. The study sample consisted of 25 adolescents from a public school and five who fulfilled socioeducational measures, all aged from 12 to 17 years. Data on the first group were collected by means of conversation circles, and on the second group by interviews. A written record was kept for both moments of data collection, which was later read and discussed among the researchers involved in the study. The results indicate some common themes emerging from circles and interviews, namely:
\end{abstract}


adolescence, anger, fear, social issues, law, and violence. When sharing their perspectives on the subject, participants went beyond an opinionated position, producing important elaborations. This also triggered the possibility of addressing specific problems of adolescence and social reality. In this scenario, Psychology plays a key role in bringing opinions to light, such as those of adolescents participating in this study - who tend to stay on the sidelines.

Keywords: Criminal Responsibility, Adolescence, Psychoanalysis, Conversation Circle, Interviews.

\title{
La Reducción de la Edad de Responsabilidad Penal desde la Perspectiva de Adolescentes
}

\begin{abstract}
Resumen: La propuesta de enmienda a la Constitución Federal (PEC 171/1993) prevé la reducción de la edad mínima de responsabilidad penal en Brasil de 18 para 16 años. Esta propuesta fue votada por la Cámara de Diputados y está actualmente en el Senado Federal, contando con intenso apoyo del actual Presidente. Aunque hay evidencias de que la edad no se relaciona con los indicadores de violencia, la opinión pública se manifiesta favorable a la medida. Por lo tanto, se considera esencial escuchar el discurso de los adolescentes sobre este tema. Este estudio tuvo como objetivo investigar la perspectiva de algunos adolescentes sobre la reducción de la edad de responsabilidad penal. Participaron 25 adolescentes provenientes de una escuela pública y cinco que estaban en cumplimiento de medida socioeducativa, todos en el grupo de edad de entre 12 y 17 años. La recopilación de datos se realizó por medio de círculos de conversación con el primer grupo y de entrevistas con el segundo. Los informes fueron escritos en ambas ocasiones. Para el análisis, los investigadores leyeron y discutieron estos informes en grupos. Los resultados muestran algunos analizadores que surgieron de los círculos y las entrevistas: adolescencia, ira, miedo, problemas sociales, derecho y violencia. Se observó que los participantes fueron más allá de una posición de opinión, produciendo elaboraciones importantes sobre el tema; esto también desencadenó la posibilidad de abordar problemas específicos de la adolescencia y la realidad social. Se considera que es una tarea única de la psicología sacar a la luz opiniones, como las de estos adolescentes, que tienden a permanecer al margen.
\end{abstract}

Palabras clave: Responsabilidad Penal, Adolescencia, Psicoanálisis, Rueda de Conversación, Entrevistas.

A proposta de Emenda à Constituição Federal (PEC) 171/1993, de autoria do deputado federal Benedito Domingos (PP-DF), propõe a alteração do artigo 228 do texto constitucional com a finalidade de reduzir a maioridade penal de 18 anos para 16 anos (Proposta de Emenda à Constituição no 171, 1993). Essa proposta foi votada em julho de 2015 na Câmara dos Deputados, tendo seguido para apreciação do Senado Federal. Após as eleições de 2018, a redução da maioridade penal se tornou uma possibilidade ainda mais real ao ser caracterizada como uma das principais medidas do atual presidente, que manifesta apoio e interesse em sua aprovação.
Desde a promulgação do Estatuto da Criança e Adolescente (ECA) em 1990, têm-se enfrentado desafios no combate à violência erigidos pela herança de um modelo punitivo-repressor. Assim, o debate sobre a redução da maioridade penal ressurge sempre que são veiculadas na mídia notícias de fatos violentos que envolvem adolescentes (Alves, Pedroza, Pino, Presotti, \& Silva, 2009)

Já em 1993 havia PEC que almejavam a alteração do artigo 228 da Constituição Federal (Campos, 2009). Em 2002, tramitavam no Congresso Nacional 14 projetos que propunham alterar a idade penal de 18 para 16 anos (Njaine \& Minayo, 2002). Em 2006, eram três 
propostas, que variavam apenas quanto à condição de aplicação de tal medida.

Em 2012, o senador Aloysio Nunes (PSDB-SP) apresentou uma PEC para alteração dos artigos 129 e 228 da Constituição. O intuito era acrescentar um parágrafo único que previsse a possibilidade, após emissão de laudo técnico, de desconsideração da inimputabilidade de maiores de 16 anos e menores de 18 anos para crime hediondos (Proposta de Emenda à Constituição no 33, 2012). Em outubro de 2013, o senador Ricardo Ferraço emitiu relatório com parecer favorável à PEC de 2012.

Em 2014, a Comissão de Constituição Justiça e Cidadania rejeitou o relatório emitido pelo senador Ricardo Ferraço. A PEC foi considerada inconstitucional, uma vez que a inimputabilidade só pode ser modificada por uma nova Assembleia Nacional por fazer parte das garantias individuais. Além disso, foi ressaltado que a redução da maioridade penal não é a solução para combater a violência. Porém, a discussão sobre a PEC teve continuidade no Senado, onde encontra-se em tramitação desde 2015 (Cavalcanti \& Oliveira, 2015).

O argumento de políticos que são favoráveis à redução da maioridade penal é que adolescentes com a partir de 16 anos devem ser responsabilizados penalmente (Cunha, Ropelatto, \& Alves, 2006), porque seriam capazes de discernir sobre o caráter de licitude e ilicitude dos atos que praticam. Ainda acrescentam aos seus argumentos o aumento do número de crimes praticados por menores de 18 anos e a falência das medidas socioeducativas. Por outro lado, profissionais do direito e da área social que atuam diretamente com crianças e adolescentes em situação de risco se posicionam contrariamente, defendendo a legislação atual, isto é, o ECA. Esta contempla uma política educacional que visa, por meio de medidas socioeducativas, promover a reabilitação e a reinserção do adolescente infrator na sociedade, considerando-o um ser em desenvolvimento (Lei no 8.069/1990).

A criação do ECA e as ações protetivas para a juventude devem ser consideradas uma conquista para o contexto brasileiro. Historicamente, apenas no início do século XX houve iniciativas para a proteção da infância "abandonada e delinquente". O Estado passa a assumir a responsabilidade de exercer a tutela oficial das crianças abandonadas. Havia um interesse político, neste momento, em tutelar estas crianças, já que não existia ainda uma regulação do trabalho infantil. As pressões por leis específicas para organizar a assistência e a proteção à criança ganharam força até culminarem, em 1927, na promulgação do "Código de Menores”. Este código tinha como característica abranger os possíveis problemas dos menores e exercer um firme controle sobre eles, retirando-os da rua e das situações de criminalidade. Além disso, seguia as tendências da época de "recolhimento e internação", tendo caráter protetivo da sociedade, e não dos jovens. A psicologia e a psiquiatria se inserem neste bojo, servindo como instrumento de avaliação física e mental dos menores recolhidos e de suas famílias (Rizzini \& Pilotti, 2009).

Apesar de inicialmente haver um forte apoio da sociedade civil ao Código de Menores, com a sua instalação e aplicabilidade ao longo dos anos através da Fundação Nacional do Bem-estar do Menor (Funabem) e da Fundação Estadual de Bem-estar do Menor (Febem), foram surgindo denúncias do uso de medidas violentas para "reeducação dos menores". Estes centros se especializaram em triar e observar os menores, intensificando o processo de criminalização e exclusão da pobreza, sem assumir uma assistência e proteção efetiva destas crianças (Rizzini \& Pilotti, 2009).

As mudanças no campo da infância e juventude ocorrem com o fim do governo militar e o início da redemocratização do país. Organizações governamentais e não governamentais nacionais e internacionais começaram a denunciar o desrespeito aos direitos das crianças no Brasil, e a atuação de movimentos sociais, juntamente com a insatisfação e a grande pressão popular, culminou na revogação do código. Surge então seu substituto de 1979, que incorpora a concepção assistencialista à população infanto-juvenil (Rizzini \& Pilotti, 2009).

Durante a elaboração da nova Constituição Federal (1988), um grupo de trabalho se reuniu para formular também um artigo para a promulgação dos direitos das crianças e dos adolescentes. $\mathrm{O}$ resultado foi o artigo 227, que serviu de base para a elaboração do ECA. Dois anos depois, em 1990, subsidiados por esses movimentos e pela ratificação dos direitos humanos na Convenção Internacional dos Direitos das Crianças promovida pela ONU em 1989, promulgou-se o ECA. O Estatuto, aprovado pelo Congresso Nacional pela Lei $\mathrm{n}^{\circ}$ 8.069/90, tem como diretrizes a igualdade, a proteção integral e o atendimento prioritário às crianças e adolescentes. Ele é considerado um documento exemplar no campo dos direitos humanos e reflete o debate de ideias e a participação de vários 
segmentos sociais envolvidos com a infância no Brasil (Nascimento, Lacaz, \& Alvarenga Filho, 2010).

Até os dias atuais vigoram os princípios do ECA, cujas diretrizes são a igualdade, a proteção integral e o atendimento prioritário às crianças e adolescentes (Lei no 8.069/1990). Apesar disso, o país ainda carrega a dicotomia "crianças/adolescentes" e "menores", o que, dentre outros fatores, atravanca o avanço nos debates, a aplicabilidade do ECA e a consequente criação de políticas públicas para esta faixa etária (Feitosa \& Boarini, 2014). O conhecimento das nuances históricas acerca da relação das crianças e adolescentes com a instância judiciária é um dos pontos a ser considerado quando se discute propostas legislativas e a criação de políticas públicas (Cruz, Hillesheim, \& Guareschi, 2005), como a redução da maioridade penal.

Atualmente, os adolescentes que cometem atos infracionais cumprem medidas socioeducativas, que são orientadas por um caráter predominantemente educativo e não apenas de sanção. Espera-se, assim, responsabilizar o adolescente por seus atos ao mesmo tempo em que se promove a reinserção social (Freitas, 2011). Constam entre as medidas: advertência, obrigação de reparar o dano, prestação de serviços à comunidade, liberdade assistida, semiliberdade e internação (Lei no 8.069/1990).

A advertência significa que o adolescente deve comparecer frente à autoridade judicial e ser por ela advertido em relação ao ato infracional cometido. Quando se aplica a obrigação de reparar o dano, o jovem deve devolver ou restituir a vítima, enquanto a prestação de serviços comunitários exige que sejam realizadas tarefas gratuitas e de interesse coletivo. A liberdade assistida implica em acompanhamento por profissionais que objetivam a reinserção familiar e comunitária, além de observar a escolarização e a possível inserção no mundo profissional. Em sentido mais restritivo, a semiliberdade incorre em privação de liberdade com acompanhamento de profissionais e participação familiar, ao passo que a internação incide em privação completa da liberdade.

Essas medidas abrangem adolescentes de $12 \mathrm{a} 18$ anos e podem se estender excepcionalmente até 21 anos. Cabe ao juiz da infância e da juventude proferir sentenças socioeducativas pertinentes à capacidade do adolescente em cumpri-las, bem como à circunstância e à gravidade do ato infracional. Seja qual for a medida aplicada, esse adolescente geralmente é encaminhado para acompanhamento nos diversos seto- res, como desenvolvimento social, educação, saúde, dentre outros que possam contribuir com seu desenvolvimento (Lei no 8.069/1990).

Dessa forma, a proposta da redução da maioridade penal, embora contemporânea, carrega profundas imbricações históricas. A partir de investigação sobre as representações sociais de parlamentares favoráveis à redução da maioridade penal, apontou-se que seus discursos em muito se assemelham ao do antigo "Código de Menores" (Real \& Conceição, 2013). Para Cunha e Oliveira (2017), há uma tendência nos últimos anos de criminalização juvenil e judicialização das relações humanas que apresenta um forte risco às ações socioeducativas, que têm, cada vez mais, sido negligenciadas em favor de ações coercitivas e correcionais, tal como no passado.

Apesar de evidências (Lins, Figueiredo Filho, \& Silva, 2016) sugerirem que a idade de imputabilidade penal não está associada à diminuição nos indicadores de violência, o projeto reducionista encontra amparo em $90 \%$ da opinião pública (Vaz \& Moreira, 2015). A perspectiva dos adolescentes foi abordada no estudo de Galvão e Camino (2011), a partir do viés do julgamento moral, tendo a maioria dos jovens se mostrado favorável. No campo científico, a partir de uma revisão sistemática de literatura, foi possível observar que a maioria das pesquisas científicas que abordam adolescentes usuários de drogas e em conflito com a lei é de natureza quantitativa e com adolescentes do sexo masculino (Schneider, Mello, Limberger, \& Andretta, 2016).

Diante de buscas em base de dados, como IndexPsi e Google Scholar, encontrou-se várias pesquisas sobre a redução da maioridade penal que abordam aspectos jurídicos, sociais, históricos e outras de abordagem quantitativa. Porém, não encontramos nessas bases de dados específicas, a partir da busca com idioma português, estudos que escutem dos próprios adolescentes o que eles pensam sobre esta questão (Cal \& Dos Santos, 2015; Campos, 2009; Feitosa \& Boarini, 2014; Nardi, Jahn, \& Dell'Aglio, 2014; Pacheco \& Hutz, 2009; Rosa \& Vicentin, 2010; Vaz \& Moreira, 2015). A escassez de pesquisas que privilegiem a escuta dos adolescentes foi um dos fatores que motivou a realização desta pesquisa, além de um embasamento psicanalítico que foque a dimensão do sujeito e sua relação com a cultura.

Nesse sentido, é fundamental a construção de pesquisas que aumentem a representatividade dos adolescentes em questões concernentes a eles e suas especifi- 
cidades. Considerando o contexto brasileiro, histórico e atual, e embasado pelos aportes teóricos da psicanálise, este estudo tem como objetivo investigar a perspectiva dos adolescentes sobre a redução da maioridade penal.

\section{Método}

\section{Participantes}

Participaram deste estudo 25 adolescentes na faixa etária entre 12 e 17 anos. Ao todo, foram 15 participantes do sexo feminino e dez do sexo masculino. Optou-se pelo recrutamento de adolescentes de contextos diversos a fim de observar padrões e/ou variações dos discursos que surjam a partir das diferentes vivências. Dessa forma, os adolescentes foram recrutados em uma escola pública e em uma instituição de referência para adolescentes em cumprimento de medida socioeducativa em liberdade assistida e prestação de serviços, ambas da cidade de Uberlândia (Minas Gerais).

Foram organizados dois grupos compostos por adolescentes da escola pública que participaram de rodas de conversa. $O$ primeiro grupo contou com sete participantes do sexo masculino e nove do sexo feminino que cursavam o sétimo e o oitavo ano na referida escola, com idade média de 13 anos. O segundo grupo contou com quatro participantes do sexo feminino, pertencentes ao projeto Telessala, com idade média de quinze anos. Já na instituição referência para adolescentes em cumprimento de medidas socioeducativas, foram cinco adolescentes, dois do sexo feminino e três do sexo masculino, com média de idade de quinze anos e que participaram por meio de entrevistas semiestruturadas individuais.

Ressalta-se que o projeto "Elevação da Escolaridade - Metodologia Telessala" é uma iniciativa do governo do estado de Minas Gerais que tem como objetivo principal reduzir as taxas de distorção idade/ ano de escolaridade e elevar a escolaridade dos alunos de entre 15 e 17 anos no ensino fundamental. Destina-se a adolescentes maiores de 14 anos e menores de 18 que apresentam, no mínimo, dois anos de distorção idade/ano de escolaridade (Secretaria de Estado de Educação de Minas Gerais, 2016).

\section{Delineamento}

Trata-se de um estudo qualitativo (Flick, 2009) com adolescentes de entre $12 \mathrm{e} 17$ anos a respeito de suas concepções sobre a redução da maioridade penal no Brasil a partir de rodas de conversa e de entrevistas semiestruturadas. Esta pesquisa contou com referencial teórico psicanalítico ao incluir o sujeito e sua subjetividade na execução da investigação. A utilização do método clínico, então, possibilitou abranger a escuta psíquica para outros contextos que não somente o espaço concreto de atendimento terapêutico (Rosa \& Domingues, 2010).

\section{Considerações éticas}

Esse projeto foi submetido ao Comitê de Ética em Pesquisa da Universidade Federal de Uberlândia, via Plataforma Brasil, sob o protocolo 55110816.3.0000.5152, e aprovado em maio de 2016. A escola pública, a instituição de referência para adolescentes em cumprimento de medidas socioeducativas e os adolescentes que tiveram interesse e disponibilidade em participar, autorizados por seus responsáveis legais, foram devidamente informados dos detalhes do presente estudo e, conforme anuência, assinaram o termo de consentimento livre e esclarecido e o termo de assentimento do menor. Os nomes dos adolescentes foram ocultados e substituídos por iniciais fictícias na apresentação das falas a fim de evitar sua identificação.

\section{Instrumentos}

Durante a pesquisa, contou-se com um roteiro semiestruturado para a condução das rodas de conversa com os participantes da escola e das entrevistas com os participantes da instituição de referência para adolescentes em medidas socioeducativas. Trata-se de um roteiro construído a partir de discussões realizadas no grupo de pesquisa e baseado no referencial teórico psicanalítico e na revisão de literatura da temática. Constavam perguntas como "Você(s) já ouviu(ouviram) falar sobre o projeto de redução da maioridade penal?", "Você(s) acredita(m) que este projeto pode reduzir os índices de violência? Por que? ", "Se você(s) não acredita(m), o que poderia ser feito para reduzir a violência?" e outras. Assim, o instrumento consistia em um roteiro com questões disparadoras a fim de possibilitar a criação de um espaço de diálogo e de discussão a respeito da redução da maioridade penal no Brasil sob a perspectiva dos participantes.

\section{Estratégia de coleta de dados}

A partir da proposta de escuta dos adolescentes no que concerne à redução da maioridade penal, optou-se inicialmente pela realização de rodas de conversa 
como meio privilegiado de coleta de dados entre esses indivíduos. A roda de conversa é entendida como uma metodologia de investigação e de intervenção na criação de espaços de diálogos, de expressão, de escuta de si e dos pares que favorece trocas de experiências entre os envolvidos (Paulino, Rodrigues, Christóforo, Rodrigues, \& Silva, 2015).

A participação coletiva é decisiva no espaço das rodas de conversa, possibilitando a circulação da palavra. Constitui-se, assim, como uma prática de grupo potente em que se viabiliza uma escuta que não se reduz às posições de poder que estão em jogo na execução de pesquisas (Oliveira, 2015). Nesse sentido, a roda de conversa é, então, uma metodologia que possibilita o confronto de realidades e que permite a ação, reflexão e transformação (Sampaio, Santos, Agostini, \& Salvador, 2014), sendo adequada aos propósitos desta investigação.

Dessa forma, realizou-se na escola duas rodas de conversa com adolescentes, cada uma com duração de 50 minutos e conduzida por dois mediadores da equipe executora, enquanto um terceiro integrante da equipe participou como pesquisador-observador, anotando falas, acontecimentos e percepções durante a atividade. Posteriormente, ao final das rodas de conversa, essas anotações foram transformadas em um relato escrito.

A execução de rodas de conversa com os adolescentes que estavam em cumprimento de medida socioeducativa foi considerada inviável a partir de discussão com a direção da instituição por questões específicas de âmbito institucional. Diante do apontado pelos gestores, foi acordado que os pesquisadores realizariam entrevistas semiestruturadas com os adolescentes individualmente.

Na instituição, entrevistou-se cinco adolescentes. As entrevistas foram realizadas por dois pesquisadores da equipe, de forma que um deles se dedicou às perguntas com os adolescentes entrevistados, enquanto o outro atuou como pesquisador-observador da mesma forma que nas rodas de conversa, fazendo anotações e, ao final, um relato escrito.

A presença do pesquisador-observador nessa pesquisa se baseia no modelo de atendimento psicanalítico conjunto pais-criança (Paravidini \& Chaves, 2012). Essa adaptação para o pesquisador-observador foi proposta na medida em que ele foi o responsável pela palavra escrita durante a condução da roda de conversa ou da entrevista. Acredita-se que o observa- dor instaura um espaço de continência a partir de sua postura receptiva de quem só olha, escuta e escreve. Ressalta-se que nas rodas de conversa e nas entrevistas foi antes explicitado aos participantes a presença do pesquisador-observador e seu papel naquele momento. Também foi garantido aos participantes que poderiam, a qualquer momento, ter acesso aos escritos do pesquisador-observador. Houve anuência para a presença do pesquisador-observador em todas as etapas da coleta de dados.

\section{Estratégia de análise dos dados}

A análise dos dados aconteceu em três momentos. No primeiro, as anotações do pesquisador-observador foram organizadas no formato de relato escrito após o fim das rodas de conversa e das entrevistas. Em seguida, os relatos do pesquisador-observador foram lidos e discutidos em grupo. Esse momento permitiu a inversão dos papéis, de forma a devolver a palavra falada para aquele que observou, dando voz à sua experiência (Paravidini \& Chaves, 2012). Como esse momento é vivenciado em grupo, possibilita-se a circulação da palavra entre todos, tanto os que executaram quanto o observador que pode, enfim, confrontar suas experiências. Dessa discussão em grupo, formou-se um novo relato escrito pelo conjunto das impressões obtidas por todos, mediadores e observadores, das rodas de conversa e das entrevistas. Por fim, o novo relato escrito foi discutido e analisado pela equipe de modo a elencar os aspectos principais dos dados, agrupando-os em torno de categorias. Essas categorias serão chamadas aqui de analisadores (Perfeito, 2007) por permitirem a compreensão aprofundada do emergido nas rodas de conversa e entrevistas a partir do referencial psicanalítico.

\section{Resultados e discussão}

A redução da maioridade penal tem se constituído como assunto polêmico, sustentado, sobretudo, pela judicialização da conduta juvenil (Cunha \& Oliveira, 2017). Nesse sentido, este estudo valoriza predominantemente a fala dos adolescentes a respeito dessa questão. Os dados gerados por meio das rodas de conversa e entrevistas possibilitaram a emergência de seis analisadores, detalhados a seguir. São eles: adolescência; raiva; medo; questão social; violência; e lei. As falas dos participantes são apresentadas seguidas de iniciais fictícias para evitar sua identi- 
ficação, da idade e do contexto da coleta de dados: escola ou MS para adolescentes em cumprimento de medida socioeducativa.

\section{Adolescência}

A partir da pesquisa, destaca-se o analisador "adolescência", abordado como um momento de conflito e de intenso trabalho subjetivo, em que questões como ter discernimento ou não de o que se faz e ser influenciado por outras pessoas podem ser problematizadas. Evidenciou-se uma vacilação entre ser influenciado por alguém e, por isso, não ter o discernimento do que se faz, como na fala: "Menor quer coisa que os pais não podem dar, aí o maior influencia ele para conseguir o que quer" (E., 13 anos, Escola) e, ao mesmo tempo, já ter a capacidade de decidir e de se responsabilizar pelos atos, como para N. (14 anos, Escola), ao afirmar que "os menores fazem coisas influenciados por adultos".

Na adolescência há uma perda de referenciais parentais, um desligamento das referências infantis e uma construção de novas referências designadas pelos pares (Alberti, 2004). Adolescentes buscam alguém para se identificar, de forma que os outros, inclusive os pares, passam a ter influência sobre ele. Isso é ilustrado pela fala de S. (16 anos, Escola/Telessala), para quem "os malas acolhem a gente".

É neste momento da adolescência em que há uma maior incidência de riscos psicossociais pelo desejo de transgredir a ordem estabelecida e pelo processo de identificação com um outro, que é importante para que o sujeito possa ampliar suas próprias escolhas e criar uma identidade própria (Saggese \& Leite, 2011).

Nas rodas de conversa e nas entrevistas, há também falas que apresentam um paradoxo próprio da adolescência que questiona a capacidade de discernimento do adolescente. Como exemplo, B. (12 anos, Escola), ao dizer que "com 16 anos já pode até votar e porque não pode assumir o erro?". Com o mesmo sentido, R. (16 anos, Escola/Telessala) afirmou "sou totalmente a favor, é certo porque temos que pagar pelos nossos erros” (R., 16 anos, Escola/Telessala). O posicionamento favorável à redução foi recorrente entre os adolescentes da escola. Contudo, à medida que a discussão evoluía, desvelou-se um paradoxo inerente à adolescência. Notou-se um dilema entre ser influenciado e ser responsável como aquele que sabe o que faz.

Os adolescentes entrevistados na instituição de medida socioeducativa tenderam a ser contrários à redução e acrescentaram ao debate "Sou contra, por- que o adolescente tem que ter todos os direitos de maior e não só o código penal" (M., 15 anos, MS) e "morre demais na prisão, porque a mente de 16 anos é diferente da mente de 30 anos" (J., 17 anos, MS).

A discussão sobre influenciar e ser influenciado é problemática e não pode ser resolvida de forma polarizada. A própria adolescência traduz um impasse fundamental como travessia da infância para vida adulta em que não se é criança e nem adulto por ser um momento muito específico da vida, com mudanças físicas, psíquicas e sociais.

Este impasse da adolescência observado nas falas dos participantes pode ser entendido a partir do conceito de adolescência moratória, como proposto por Calligaris (2000). Ela é caracterizada como um período de crise em que, apesar de o indivíduo sentir que está fisicamente preparado para a vida adulta e almejar sua liberdade, ele ainda ficará tutelado por seus pais ou outro, pois os adultos ainda não o reconhecem com maturidade. Seria então um momento de preparação para a vida adulta, no qual estariam suspensas as obrigações e dificuldades em detrimento de uma preparação para realização de escolhas. Assim, o adolescente conservaria características do mundo infantil e adulto.

\section{Raiva}

A raiva foi outro importante analisador emergido das rodas de conversa e entrevistas. Os adolescentes problematizaram a raiva como um disparador de violência. Para B. (13 anos, Escola), as pessoas cometem crimes "é pra 'descontar' a raiva". Durante diversos momentos, eles apontaram a raiva como motivação para a criminalidade, ao passo que outros adolescentes contemporizavam, trazendo formas de lidar com esse sentimento. Entre esses jeitos, foram citados: jogos on-line, vícios diversos, a internet e, também, a palavra.

As falas dos participantes remetem à raiva enquanto um sentimento intrínseco ao sujeito, como para M. (14 anos, Escola), que afirma que sentir raiva é coisa de "pessoa que não tem psicológico bom", ou para J. (12 anos, Escola), para quem o roubo pode ser “por prazer ou raiva da vida".

Nesse sentido, encontra-se amparo na leitura freudiana, para quem a raiva é constitutiva do ser humano (Freud, 1930/2010b). Tem-se que, para viver em civilização, o homem teve que renunciar às inúmeras exigências da satisfação pulsional em prol da sociedade. 
Por essa condição de viver coletivamente, o sofrimento é inevitável, pois o sujeito se depara com uma luta constante entre a satisfação da pulsão e ser submetido às restrições impostas pela comunidade. Assim, o homem busca medidas paliativas para aliviar o mal-estar como os derivativos, as satisfações substitutivas e as substâncias tóxicas. Exemplo disso é a fala de R. (13 anos, Escola), para quem "tem jeitos e jeitos para descontar a raiva. Pode descontar nas palavras". Outras medidas foram citadas pelos adolescentes como o uso de substâncias psicoativas, os jogos de videogame e os próprios espaços mediados pela palavra.

Outro aspecto a se considerar é o que Canelas Neto (2018) propõe sobre o fracasso do trabalho de pensamento crítico atual. Embalado pelo afeto do ódio, o pensamento é contaminado, de forma a impedir um verdadeiro trabalho de pensar, fundamental para não tornar as palavras banalizadas. Ao questionarem a origem dessa raiva, os mediadores obtiveram como resposta a vivência de situações traumáticas contrapostas a uma visão biologizante do ser humano, expressa por meio de falas como "a pessoa não ter um bom psicológico" ou "nascer assim". Isso aponta para a atribuição, por parte dos participantes, de uma dimensão do mal que faz parte de todos os humanos.

Essa dimensão encontra ressonância no trabalho sobre as "Pulsões e destinos das pulsões" (Freud, 1915/2010a). Nesse texto, mais precisamente na última parte, quando descreve a relação entre o amor e o ódio para o psiquismo, Freud (1915/2010a) esclarece que o ódio não seria uma espécie de um amor negativo, tal como se poderia supor pela aparente mutação do ódio em amor, pois o ódio teria, na verdade, uma gênese própria. Em outras palavras, o ódio derivaria da luta do ego por sua conservação e afirmação. Para tanto, a agressividade pode ser considerada como uma afirmação da vida, sem a qual a morte se apoderaria do psiquismo (Birman, 2006).

Com o espaço de diálogo criado nas rodas e nas entrevistas, foi possível trazer elementos para pensar a relação entre a raiva e a criminalidade perpassados pelos participantes, que apontaram jeitos de lidar com a violência que não passam pelo crime. Segundo Freud (1930/2010b), a existência no homem de uma inclinação para a agressão faz com que a civilização dispenda esforços para estabelecer limites e controlar tais manifestações, evitando, por sua vez, a extinção do indivíduo e da sociedade.
Ao longo desses momentos, foi possível observar uma conexão entre o afeto que gera o ato, a violência. A partir da mediação e da contraposição dos próprios participantes, inaugurou-se um espaço para pensar que esse afeto ligado ao ato e à infração pode ou não induzir a criminalidade, havendo outras formas de expressá-lo.

\section{Medo}

O medo apareceu nas discussões com os adolescentes como uma barreira à possibilidade do ato criminoso. À medida que se começou a problematizar a redução da maioridade penal, a concretude da proposta foi questionada pelos adolescentes, de modo que questões de ordem prática passaram a ocupar espaço no diálogo. Na escola, foi comum observar perguntas dessa ordem como "Vão para o reformatório?" (G., 13 anos, Escola) ou "Como faz com adolescentes numa cadeia normal? Como funciona?” (E., 13 anos, Escola).

Os adolescentes que se mostravam a favor da redução, em certo ponto da roda de conversa, questionaram os mediadores como se efetivariam as penas para adolescentes em conflito com a lei, caso a redução da maioridade penal fosse aprovada. Por exemplo, B. (13 anos, Escola), que, apesar de afirmar-se favorável à redução no início, durante a discussão afirmou “Mas, se vai ficar junto com adulto, vai ficar pior. Não devia ficar junto". Diante da resposta dos outros participantes e das intervenções dos mediadores, esses adolescentes passaram a problematizar as condições prisionais do país para abrigar os jovens. O medo de ser preso junto com adultos é disparador para outros medos advindos dessa possível situação, como o medo de morte, da violência sexual, de não ter necessidades básicas supridas e da loucura. Soma-se a isso que, a partir do medo, parece abrir-se espaço para pensar sobre outras condições impostas pelo cárcere, como o sofrimento dos parentes, a perda da condição de proteção social, o medo da prisão e a loucura.

Observa-se que o medo do adulto foi disparador para expor a condição de desamparo inerente ao humano tanto nas rodas de conversa quanto nas entrevistas. A situação originária do desamparo do recém-nascido é arquetípica e tende a se repetir em inúmeras outras situações ao longo da vida (Rocha, 1999). Assim, o encarceramento ao lado de um outro percebido como mais forte resvala na própria construção da civilização, dada as renúncias pulsionais, tangenciando a angústia advinda desse encontro. 
É interessante observar que, na escola, os adolescentes manifestaram seu medo e a constatação de que ao ficar preso com o adulto, o adolescente estaria em risco. Nas entrevistas com os adolescentes em cumprimento de medida socioeducativa, nota-se o mesmo sentimento, porém baseado nas próprias experiências, como denota a fala de A. (15 anos, MS) "Na colônia [presídio para adultos] não é lugar nem de bicho. Se o adulto não gosta de você, você é morto". Outro adolescente corrobora a fala de M., afirmando que "[o adolescente] vai ser morto ou ficar doido na colônia." (M., 16 anos, MS). Mais interessante ainda é a fala de J. (17 anos, MS) que afirma: "ele [o adolescente] é fera, mas não é leão". Por essa fala, identifica-se, além de uma suposta natureza feroz, cruel e selvagem, o reconhecimento de uma superioridade do adulto à qual o adolescente ainda não ascendeu.

Assim, ao abordar o adulto e a convivência imposta na prisão junto a ele, caso a proposta da redução se efetive, constata-se uma virada no diálogo em que a possível dominação do adulto é vista como assustadora. Percebe-se que o adulto causa medo e possibilita ao adolescente pensar sobre outra perspectiva, contraposta a este adulto que parece superior e amedrontador.

Pode-se compreender essa discussão também a partir de uma concepção histórica, segundo a qual a sociedade visa punir os "condenáveis" por meio de ações de recolhimento e de internação, afastando-os do convívio social e não lhes propiciando formas de reabilitação e reinserção social. O cárcere traz consigo a representação de uma vivência violenta e amedrontadora, disparadora de angústia e desamparo, e faz com que o indivíduo se depare com uma situação de fragilidade e vulnerabilidade. Rizzini e Pilotti (2009) apontam que, por um longo período histórico, o Estado teve uma postura punitiva e de controle social pelo encarceramento de crianças e adolescentes pobres e que viviam em situação de rua. Por vezes, vivenciavam-se atos de violência travestidos de "reeducação dos menores", sem que fossem oferecidas condições para que eles tivessem a possibilidade de uma vida melhor.

Nesse sentido, a própria redução da maioridade penal, como posta atualmente, parece se constituir como uma forma de punir os jovens, em que o Estado se desresponsabiliza por ações de proteção integral ao adolescente e continua perpetuando uma condição de exclusão dos “condenáveis".

\section{Questão social}

A questão social também aparece como um importante analisador, especialmente no segundo grupo, composto por alunas do projeto Telessala. Reitera-se que esse projeto é composto por estudantes que estejam com distorção entre idade e escolaridade (Secretaria de Estado de Educação de Minas Gerais, 2016). Não obstante, a questão social salta como analisador justamente nessa roda de conversa. A exclusão vivenciada pelos alunos que cursam a Telessala foi exposta, de forma que se demonstraram as condições de marginalização e segregação que vivem não só no âmbito da escola, mas também no social. São alunos adjetivados pelos profissionais da escola como "problemáticos", "rebeldes" e que se envolvem em situação de risco social. Parece que o imaginário desses profissionais é composto por um descrédito diante das potencialidades que esses adolescentes apresentam.

Isso é possível de se notar pela própria configuração espacial do projeto Telessala na escola. Os alunos pertencentes a esse projeto ficam em uma sala em um andar inferior na escola, apartada das outras salas de aula. Embora seja um programa que visa a inclusão, está em seu cerne também a exclusão. Entende-se que a sociedade exclui para incluir, de forma que este processo é dialético e constitutivo de uma ordem social que é, por sua vez, desigual (Sawaia, 2001). Identifica-se que há, pela legislação, uma tentativa de incluir esses alunos, mas eles acabam por vivenciar primordialmente práticas de segregação.

Nesse sentido, nas rodas e entrevistas, surgiram diversas falas relacionadas a vivências de situações de privação econômica, de acesso a bens de consumo e de grupos de amigos. Ao contrapor uma colega que afirmava ser favorável a pena de morte, G. (16 anos, Escola/Telessala) respondeu "É muito fácil condenar, mas tem que puxar raiz, ninguém vê o que ele [adolescente] passou".

O tráfico de drogas apareceu como representando a possibilidade de acesso a dinheiro, a roupas de marca, a videogames, a drogas e, ainda, a uma certa segurança, à amizade e a uma turma de amigos com quem se identificar, como afirma T. (15 anos, MS): "fiz o corre uma vez. Sei que não é bom, é perigoso e não compensa, dá pouco dinheiro". Observa-se, assim, que "fazer o corre" não é determinado somente pelo objetivo financeiro, $o$ que retoma o fato de o adolescente buscar referências em seus pares para constituir sua identidade e construir novos laços sociais (Alberti, 2004). 
Por muitos momentos, os participantes abordaram a questão social, o tráfico de drogas e a criminalidade, atribuída na adolescência à falta de espaços sociais que permitam uma inclusão de indivíduos que vivem em situação de vulnerabilidade social. T. (15 anos, MS) ilustra bem essa situação ao afirmar "eu vivo no mundão e no mundão tem muita droga".

A história de N. (13 anos, MS) ilustra a questão social que perpassa essa discussão. O menino, que mora em um dos bairros mais periféricos da cidade, contou aos pesquisadores sobre a separação dos pais que afastou toda a família, assim como sobre a saída do pai de casa e a solidão que é viver com sua mãe. Seu irmão de 19 anos se tornou sua referência, embora hoje esteja preso. N. não sabia do que se tratava a redução da maioridade penal. Quando os pesquisadores explicam a ele, o menino apenas diz "Acho isso ruim. Eu não quero ser preso". A fala de N. transmite angústia ao indicar que, para alguns adolescentes, existem condições sociais que estreitam caminhos e possibilidades. Além disso, nos faz questionar o papel educativo e informativo que a instituição para cumprimento de medidas socioeducativas tem desempenhado.

Também nesse sentido, surgiu na roda de conversa da Telessala alternativas ao tráfico, marcadas pela reivindicação de que "tinha que ter trabalho 'pra todos os menor" (R., 16 anos, Escola/Telessala). As adolescentes desse grupo citaram oportunidades de trabalho e projetos sociais como possibilidade de espaços que integram o adolescente e evitam a criminalidade. Ainda, fizeram também uma denúncia ao expor diversos projetos que paulatinamente têm sido desmontados e fechados, deixando inúmeros jovens sem assistência. Ressalta-se, novamente, a tensão entre inclusão e exclusão que perpassa constantemente a vida desses adolescentes.

\section{A lei}

"A Lei" é mais um analisador que se destacou entre os dados. Esta foi abordada em várias dimensões: na discussão que suscitou esclarecimento informativo sobre o projeto de lei da redução da maioridade penal; nos posicionamentos favoráveis e contrários à redução da maioridade penal; na vivência da aplicabilidade de uma medida socioeducativa como prevista no ECA; e na sobre discussão se com a aprovação do projeto de lei da redução da maioridade penal, esses adolescentes seriam aqueles que vivenciariam na prática a punição prevista; e no embate entre a lei do tráfico e a lei da cadeia.
Tanto nas rodas de conversa quanto nas entrevistas foi abordado o conhecimento dos adolescentes sobre o projeto de lei foco desta pesquisa e, em alguns momentos, foi importante esclarecer as informações a respeito dele. A maioria dos participantes já tinha ouvido falar sobre o tema. Durante o desenrolar das discussões, muitos se posicionaram de forma favorável ou contrária à medida e desenvolveram algumas sugestões, como a de J. (12 anos, Escola): "em vez de reduzir, podia ficar dentro de casa". Como tratamos nos analisadores anteriores, eles conseguiram fazer elaborações para além de uma discussão polarizada entre contra ou a favor da redução da maioridade, pautando uma reflexão mais ampliada e aprofundada do tema, evidenciando a capacidade reflexiva potente desses adolescentes.

Nas entrevistas realizadas com os adolescentes em cumprimento de medida socioeducativa, foi possível nos aproximar daqueles jovens que vivenciam a aplicabilidade de uma medida prevista pelo ECA (Lei $\left.\mathrm{n}^{\circ} 8.069 / 1990\right)$ diante de um ato infracional cometido. Essa lei, cujas diretrizes são o atendimento prioritário, a igualdade e proteção integral, só pôde ser elaborada, segundo Cirino (2001), a partir da mobilização de movimentos e frentes de defesa pelos direitos de crianças e adolescentes. Ela é um avanço em termos políticos, pois reflete uma responsabilização do Estado em promover ações de proteção da infância e adolescência que valorizam suas especificidades e contemplam sua complexidade.

Existe uma ação que promove tanto a responsabilização do adolescente pelo ato infracional cometido quanto uma responsabilização do Estado em promover atenção integral e proteção a esses adolescentes. Ou seja, há uma tentativa de reeducar estes adolescentes sem os excluir. Mas podemos extrair de suas falas que, na prática, há uma tensão entre inclusão e exclusão: "A lei é para todo mundo" (J. 14 anos, Escola); "A lei não se cumpre" (S., 16 anos, Escola/ Telessala), ou como delineado na fala de T. (15 anos, MS), "eles [os políticos] não sabem o que a gente passa. Isso não ia resolver".

O ECA, a partir da proposição das medidas socioeducativas, tenta garantir a não exclusão dos jovens do convívio social, rompendo, na teoria, com um imaginário acerca da delinquência. No entanto, na prática, essa exclusão ocorre de maneira "extraoficial", circulando, principalmente, na maneira como a lei é aplicada. Assim, o processo de marginalização desses 
jovens acontece nas formas da estigmatização social e da culpabilização do indivíduo.

O ECA visa a garantia de direitos próprios a todas as crianças, os "sujeitos de direitos", almejando colocar fim a um sistema segregatório e totalitário para a infância, partindo do princípio de inclusão de todas as crianças e adolescentes em seu sistema protetivo. Porém, na prática, ele repete a lógica de marginalização, pois coloca as crianças infratoras ao mesmo tempo dentro e fora da lei (Pacheco, 2015).

Este hiato denuncia como as proposições e práticas de inclusão não se sustentam plenamente porque muitas vezes carregam no seu bojo o princípio de eliminação das diferenças. Segundo Voltolini (2005), a inclusão tem um resto do qual não se pode escapar. Ela não se restringe à questão dos direitos e do acesso aos bens da cidade, de modo que essa questão é não-toda a inclusão, tendo essa "um lado terminável e outro interminável” (Voltolini, 2005, p. 155).

Kupfer (2005) tece críticas e reflexões acerca da defesa da inclusão incondicional que se instala ao lado da defesa da igualdade e que precisa ser feita a qualquer custo. Para a psicanálise, há um paradoxo a ser sustentado nos princípios de igualdade, visto que a diferença está na base da constituição da subjetividade e da civilização. Esse é o paradoxo do tratamento igual que propicia o aparecimento das diferenças subjetivas. A igualdade na lei simbólica, na estrutura geral, pode fazer surgir a diferença ou a singularidade. São as "diferenças subjetivas na apreensão do mundo ... que permitem o surgimento de seus estilos e, portanto, do novo. Um novo singular que poderá retornar ao social para revigorá-lo" (Kupfer, 2005, p. 23).

Assim, a proposta das medidas socioeducativas baseada no princípio da reeducação e no discurso pedagógico abre brechas para o remonte de um ideal de adolescente, negando a diversidade e o desejo de cada sujeito (Gomes \& Lima, 2012).

Faz-se necessário considerar que os adolescentes entrevistados seriam aqueles que, com a aprovação do projeto de lei da redução da maioridade penal, vivenciariam na prática a punição proposta - o encarceramento. Eles se apresentaram, de forma geral, contrários à redução da maioridade penal e problematizaram questões sociais, como a vivência da exclusão e de marginalização, as histórias de abandono afetivo por parte das famílias, a vulnerabilidade social e a pouca disponibilidade de recursos de educação, trabalho, lazer e cultura. A fala de M.
(15 anos, MS) aponta, justamente, para a vivência e o entendimento da realidade do encarceramento: "tem muita diferença entre ficar com os adolescentes e os adultos. Meu amigo que passou pela prisão dos adultos ficou 'chapado das ideias', quando saiu só ficava calado, não falava nada".

Ainda na instituição para cumprimento de medidas socioeducativas, P. (16 anos, MS) aponta uma posição interessante. $\mathrm{O}$ adolescente afirma ser contra a redução da maioridade penal, mas acredita que talvez essa lei possa reduzir os índices de violência. " $O$ cara antes de fazer a coisa errada vai pensar: 'eu vou para a prisão com os adultos e não com adolescentes. A de adolescentes é uva, cinco refeições por dia, conforto... vai pensar bem antes do crime".

Outro aspecto a se considerar é que na segunda roda de conversa, conduzida com adolescentes pertencentes ao projeto Telessala, a lei foi um analisador importante que atravessou a discussão. A lei, no ponto de vista desses adolescentes, se apresenta como uma contraposição entre a lei do Estado e do território. Diferente dos adolescentes da primeira roda de conversa, os da Telessala apresentam experiências de vida perpassadas pelas vivências na rua. São adolescentes, em sua maioria, que têm conflitos familiares importantes e que já se envolveram com o uso de drogas e a criminalidade. Para S. (16 anos, Escola/Telessala), "eu entrei no mundo das drogas porque eu quis, mas os meus amigos bandidos mesmo falaram para não usar". É interessante observar que S. também faz uma diferenciação entre o que são os "bandidos errados" que matam ou praticam pedofilia e os "bandidos certos" que atuam no tráfico de drogas.

As adolescentes também relataram histórias em que recorreram à polícia ("a lei dos homens"), mas que não puderam contar com seu auxílio, como aparece na fala de S. (16 anos, Escola/Telessala): “Tenho ódio de polícia, vocês sem farda ok, mas com farda vocês são um lixo". Configura-se, então, uma lei que não acontece, que não se impõe e/ou colabora. Por outro lado, "a lei do tráfico", em suas falas, representa a lei que, de fato, acontece, que cria uma barreira e que, muitas vezes, também protege. Problematiza-se, assim, que a "lei dos homens" legitima a condição de segregação vivenciada no cotidiano da escola e da vida, ao passo que se fortalece uma outra lei que, ao mesmo tempo que protege, também é aplicada de maneira concreta e totalmente rígida, pois são relatadas histórias em que "o tráfico não perdoa, errou tem que pagar" (T., 
15 anos, MS). Ou seja, esses adolescentes, que ainda estão se constituindo e que possuem fragilidades psíquicas, ficam, em certa medida, desamparados ou ameaçados por essa lei que não se apresenta como protetora e organizadora.

\section{Violência}

A violência é um analisador que, de certa forma, perpassa todos os outros. As falas dos participantes apontam para a dimensão de transgressão da violência, ao mesmo tempo que apresentam o ato como forma de denúncia da vulnerabilidade social vivenciada pelos jovens que cometem atos infracionais. Nesse sentido, eles abordam a raiva como geradora de situações de violência e o ato infracional como denúncia da exclusão.

Além da dimensão de transgressão, a violência foi abordada pelos adolescentes sob a perspectiva de uma dimensão mortífera presente em seus cotidianos de forma institucionalizada, por exemplo, em práticas policiais. S. (16 anos, Escola/Telessala) afirma: “Os polícia leva os menor 'pro' meio do mato e quebra eles no meio, eu mesmo tenho marca". A mesma adolescente conta uma história de um menino ameaçado em seu bairro e para quem ela acionou a polícia, mas ela não veio. Ela ajudou o menino a escapar e saiu à procura do carro que faz a ronda no bairro, e fala indignada do descaso com que foi tratado seu pedido de socorro. S. conclui que a polícia não trata pobres e ricos de forma igual. O relato de S. mostra uma adolescente que protagoniza a narrativa de quem se afeta pela lei que legitima a segregação e que já está posta dentro do cotidiano da escola e da vida.

A partir dos dados, foi possível notar também que a violência tem uma dimensão de comunicação para os adolescentes à medida que, para eles, é uma forma fundamental de ser ouvido. Assim, nas rodas de conversa e entrevistas, a violência parece relatar uma posição marginal vivida por esses adolescentes. É necessário contextualizar essa posição de exclusão e vulnerabilidade social, na qual demandam um enorme dispêndio de violência para serem reconhecidos. Observa-se, então, que a violência aparece como uma forma de reivindicação e de denúncia daquilo que não se faz ouvir pela sociedade.

É interessante demarcar que a violência institucionalizada no cotidiano de parte da sociedade aparece nas falas de alguns adolescentes também como uma resposta de intervenção contra as próprias práticas violentas da criminalidade. Há um paradoxal voto de morte contra aqueles que transgridem as delimitações da lei do crime. Como afirma T. (15 anos, MS) "as pessoas morrem por divida e conversa fiada". Então, se por um lado, a violência pode ser entendida nas falas como um ato de se fazer ouvir, por outro, ela parece delinear um movimento que endossa um desejo de fazer calar.

Em última instância, um corpo morto é um corpo destituído de seu poder fala, seja por palavras, seja por atos de transgressão. A pena de morte, mencionada por uma das adolescentes, é uma pena de silêncio, de apagamento do desejo. Precisa-se questionar se, de fato, ainda que por vias não legislativas, a pena de morte não está se fazendo cumprir para esses jovens que vivem à margem do socialmente aceitável. Não estariam, muitos deles, pagando com a vida diante do violento desejo de se fazer ouvir?

A violência, então, pode ser aqui sustentada em ao menos duas dimensões: um meio de gritar que há algo de errado para uma sociedade que resiste a escutar suas próprias incoerências e, antagonicamente, como um dispositivo de silenciamento desses jovens transgressores. Essa segunda implicação discursiva da violência é justamente a que se esforça para radicalizar a condição marginal desses jovens-resíduos. Em sua atuação mais cruel, a violência se apresenta como um meio de marginalizar ainda mais, fazendo com que essas pessoas permaneçam não só à margem da sociedade, mas também à margem da palavra, à margem do desejo, à margem da vida.

Após a discussão dos seis analisadores aqui trabalhados, cabe ainda demarcar algumas distinções e semelhanças entre as falas dos adolescentes em cumprimento de medida socioeducativa e as falas dos adolescentes da escola e do projeto Telessala. Para isso, é imprescindível levar em consideração os diferentes contextos em que foram ouvidos, as diferentes trajetórias que os marcam e como essas disparidades convergem inevitavelmente para essa condição compartilhada do adolescer.

Uma diferença crucial que precisa ser registrada diz respeito ao local e ao formato em que os dois grupos foram ouvidos. Enquanto os adolescentes da escola e do projeto Telessala foram ouvidos na instituição de ensino, ambiente com o qual estão muito familiarizados, os participantes que cumprem medidas socioeducativas foram entrevistados em uma instituição municipal referência para adolescentes em cumprimento de tais medidas. Em relação ao formato, aqueles que 
cumprem as medidas socioeducativas foram ouvidos sozinhos ou acompanhados de seus responsáveis. Os adolescentes da escola, ao contrário, foram ouvidos em grupos formados por outros colegas de escola.

A diversidade de local e formato nos ajudam a demarcar uma primeira diferença. A fala dos adolescentes da escola e do projeto Telessala foram expressas em um contexto de debate em que claramente alguns daqueles que nunca tiveram contato com a criminalidade tentavam formular hipóteses para as questões propostas pelos pesquisadores. Por outro lado, delineando uma interessante heterogeneidade discursiva, outros adolescentes compartilhavam suas vivências diretas ou indiretas com os efeitos da criminalidade, como observado no grupo da Telessala. Nessa roda específica, notou-se um confronto entre adolescentes favoráveis e contrárias à medida da redução, com posições intensamente perpassadas pelas vivências individuais em relação a bandidos, polícia e oportunidades de trabalho. O grupo da Telessala foi marcado por um mal-estar de histórias de exclusão que não unem, mas acirraram os posicionamentos de vida.

Já as falas dos adolescentes em cumprimento de medidas socioeducativas não foram tão heterogêneas. $\mathrm{O}$ fato de estarem falando dentro de uma instituição que representa uma proposta de reabilitação pode ter influenciado em falas desconfiadas, muitas vezes marcadas por argumentações baseadas na ameaça. Diferentemente do contexto de debate, as entrevistas individuais apontaram para posturas mais homogêneas de jovens que já experienciaram diretamente alguma relação com a criminalidade. Não é por acaso que a maioria das falas desses jovens foi agrupada em um analisador: medo.

Dessa forma, notou-se que a roda de conversa propiciou espaço de debate e reflexão, mesmo em contexto de acirramento. Destaca-se o fato de que a escola, como ambiente democrático e de aprendizagem, é um espaço primordialmente convidativo à reflexão que possibilita o pensamento crítico. Sob outra perspectiva, as entrevistas e as respostas dos adolescentes em cumprimento de medida socioeducativa foram atravessadas por um tom persecutório e mais opinativo. Foi evidente o maior desconhecimento desses adolescentes sobre a proposta de redução da maioridade penal quando comparados aos adolescentes da escola e da Telessala.

A despeito das diferenças acima descritas, uma semelhança une os adolescentes participantes da pes- quisa. A nula representatividade que ambos os grupos vivenciam nas discussões que irão definir a maneira futura com a qual nossa sociedade irá lidar com os atuais impasses a respeito das propostas de redução de maioridade penal.

\section{Considerações finais}

Os analisadores foram importantes guias para a compreensão do fenômeno estudado. A partir deles, foi possível nortear a discussão e direcionar para a escolha adequada da estratégia de coleta de dados: as rodas de conversa e as entrevistas. Observou-se que a partir dessas estratégias foi possível a criação de um espaço destinado ao diálogo, à reflexão e à problematização do tema da pesquisa. Isso ficou evidente durante a condução das rodas de conversa e das entrevistas, visto que, a partir de um papel de mediação, os próprios participantes afirmavam sua posição e refletiam sobre ela, produzindo importantes elaborações. Devido a isso, não foi raro observar adolescentes que reviam suas posições durante a discussão. A fala dos mediadores e, especialmente, as contraposições apontadas pelos colegas proporcionaram um espaço de diálogo profícuo que possibilitou a construção de conhecimento conjunto.

Considera-se uma limitação deste estudo o fato de não ter sido possível realizar rodas de conversa com os adolescentes que estavam em cumprimento de medida socioeducativa. Devido a questões institucionais, a coleta de dados com esses adolescentes ocorreu somente por meio de entrevistas. Assim, uma sugestão para estudos futuros é ampliar a utilização das rodas de conversa como estratégia de coleta de dados com adolescentes para outros âmbitos. Embora tenham sido utilizadas duas formas de coleta, é importante ressaltar que esse é um dos primeiros estudos nacionais a abordar a problemática da redução da maioridade penal a partir da perspectiva dos adolescentes e de suas falas. Assim, embora tal proposta de lei os afete diretamente, são escassos os trabalhos que se destinam a escutá-los.

Acredita-se que a originalidade e a riqueza encontrada no campo de pesquisa se devem ao fato de os mediadores terem mantido o grupo enquanto reflexivo, em que a dúvida foi sustentada todo o tempo. Obteve-se, assim, uma relevância (in)formativa que colocou a problemática da redução da maioridade penal em pauta com os próprios adolescentes em uma instância coletiva e sem caráter repressor. A lei e a violência perpassaram toda a discussão, constituin- 
do-se como analisadores importantes que indicam a necessidade de mais estudos dedicados a escutar, distanciando-se da sustentação por julgamento morais.

Para finalizar, retoma-se a fala de uma participante que agradeceu aos mediadores por terem ofertado o espaço para os adolescentes se posicionarem e discutirem sobre a redução da maioridade penal. Este estudo aponta para a possibilidade concreta de uma pesquisa compromissada de forma ética e política ao restituir o direito de fala a quem o detém, mas que acaba eclipsado, muitas vezes, pela condição de vulnerabilidade social. Frente a isso, é tarefa ímpar da psicologia jogar luz e trazer para o centro da questão as opiniões que tendem a ficar à margem. Espera-se que este estudo contribua tanto para o conhecimento científico como para os próprios adolescentes, ao escutar os sujeitos para torná-los autores, tanto de suas próprias histórias quanto das histórias sociais que são construídas cotidianamente.

\section{Referências}

Alberti, S. (2004). O adolescente e o outro. Zahar.

Alves, C., Pedroza, R., Pinho, A., Presotti, L., \& Silva, F. (2009). Adolescência e maioridade penal: Reflexões a partir da psicologia e do direito. Revista Psicologia Política, 9(17), 6783. http://pepsic.bvsalud.org/pdf/rpp/v9n17/v9n17a05.pdf

Birman, J. (2006). Arquivo da agressividade em psicanálise. Natureza Humana, 8(2), 357379. http://pepsic.bvsalud.org/ $\mathrm{pdf} / \mathrm{nh} / \mathrm{v} 8 \mathrm{n} 2 / \mathrm{v} 8 \mathrm{n} 2 \mathrm{a} 05 . \mathrm{pdf}$

Calligaris, C. (2000). A adolescência. Publifolha.

Cal, D. G. R., \& Dos Santos, B. A. M. (2015). Adolescentes infratores na cena pública: Como os media alimentam o debate sobre a redução da maioridade penal. Contemporânea Revista de Comunicação e Cultura, 13(1), 140. https://doi.org/10.9771/contemporanea.v13i1.13151

Campos, M. S. (2009). Mídia e política: A construção da agenda nas propostas de redução da maioridade penal na Câmara dos Deputados. Opinião Pública, 15(2), 478509. https://doi.org/10.1590/S0104-62762009000200008

Canelas Neto, J. M. (2018, 24 de outubro). Psicanálise e formação de massa. Blog de Psicanálise: Sociedade Brasileira de Psicanálise de São Paulo. https://www.sbpsp.org.br/blog/psicanalise-e-formacao-de-massa/

Cavalcanti, M. F., \& Oliveira, I. F. (2015). Maioridade penal: A urgência de uma discussão. Revista Subjetividades, 15(2), 257264. https://doi.org/10.5020/23590777.15.2.257-264

Cirino, O. (2001). Psicanálise e psiquiatria com crianças: Desenvolvimento ou estrutura. Autêntica.

Constituição da República Federativa do Brasil de 1988. (1988). Senado Federal. https://www.senado.leg.br/ atividade/const/con1988/CON1988_05.10.1988/CON1988.asp

Cruz, L., Hillesheim, B., \& Guareschi, N. M. F. (2005). Infância e políticas públicas: Um olhar sobre as práticas psi. Psicologia \& Sociedade, 17(3), 4249. https://doi.org/10.1590/S0102-71822005000300006

Cunha, K. R., \& Oliveira, M. C. (2017). Adolescências e judicialização da conduta juvenil. Barbarói, 50, 107130. https://doi.org/10.17058/barbaroi.v0i0.11143

Cunha, P. I., Ropellato, R., \& Alves, M. P. (2006). A redução da maioridade penal: Questões teóricas e empíricas. Psicologia Ciência e Profissão, 26(4), 646659. https://doi.org/10.1590/S1414-98932006000400011

Feitosa, J. B., \& Boarini, M. L. (2014). The defense of socio-educational internment: Feature of the hygienist principles. Paidéia (Ribeirão Preto), 24(57), 125133. https://doi.org/10.1590/1982-43272457201415

Flick, U. (2009). Qualidade na pesquisa qualitativa. Artmed.

Freitas, T. P. (2011). Serviço social e medidas socioeducativas: O trabalho na perspectiva da garantia de direitos. Serviço Social \& Sociedade, (105), 3049. https://doi.org/10.1590/S0101-66282011000100003

Freud, S. (2010a). As pulsões e seus destinos (P. C. Souza, Trad.). Companhia das Letras. (Trabalho original publicado em 1915).

Freud, S. (2010b). O mal-estar na civilização (P. C. Souza, Trad.). Companhia das Letras. (Trabalho original publicado em 1930).

Galvão, L., \& Camino, C. (2011). Julgamento moral sobre pena de morte e redução da maioridade penal. Psicologia \& Sociedade, 23(2), 228236. https://doi.org/10.1590/S0102-71822011000200003 
Gomes, C., \& Lima, M. (2012). Psicanálise e inclusão escolar: Considerações acerca dos atuais discursos e da equação família e escola. IX Colóquio do LEPSI, São Paulo. http://www.proceedings.scielo.br/pdf/lepsi/n9/a38n9.pdf

Kupfer, M. (2005). Inclusão escolar: A igualdade e a diferença vistas pela psicanálise. In F. Coli, \& M. Kupfer (Orgs.), Travessias inclusão escolar: A experiência do grupo ponte: pré-escola terapêutica lugar de vida (pp. 17-28). Casa do Psicólogo.

Lei n. 8.069, de 13 de julho de 1990. (1990, 16 de julho). Dispõe sobre o Estatuto da Criança e do Adolescente e dá outras providências. Diário Oficial da União. http://www.planalto.gov.br/ccivil_03/leis/l8069.htm

Lins, R., Figueiredo Filho, D., \& Silva, L. (2016). A redução da maioridade penal diminui a violência? Evidências de um estudo comparado. Opinião Pública, 22(1), 118139. https://doi.org/10.1590/1807-0191201622118

Nardi, F. L., Jahn, G., \& Dell'Aglio, D. (2014). Perfil de adolescentes em privação de liberdade: Eventos estressores, uso de drogas e expectativas de futuro. Psicologia em Revista, 20(1), 116137. https://doi.org/10.5752/ P.1678-9523.2014v20n1p116

Nascimento, M. L., Lacaz, A. S., \& Alvarenga Filho, J. R. (2010). Entre efeitos e produções: ECA, abrigos e subjetividades. Barbaroi, (33), 5064. https://online.unisc.br/seer/index.php/barbaroi/article/view/1521/1315

Njaine, K., \& Minayo, M. C. S. (2002). Análise do discurso da imprensa sobre rebeliões de jovens infratores em regime de privação de liberdade. Ciência \& Saúde Coletiva, 7(2), 285297. https://doi.org/10.1590/S1413-81232002000200009

Oliveira, G. M. D. (2015). No descomeço era o verbo: Um convite a Manoel de Barros para a roda de conversa na educação infantil [Dissertação de Mestrado, Universidade de Brasília]. Repositório UnB. http://repositorio.unb.br/ handle/10482/18457

Pacheco, A. (2015, 23 de junho). A criança como sintoma: Mal-estar no Brasil. Movimento Psicanálise, Autismo e Saúde Pública. https://psicanaliseautismoesaudepublica.wordpress.com/2015/06/23/ a-crianca-como-sintoma-mal-estar-no-brasil/

Pacheco, J. T., \& Hutz, C.S. (2009). Variáveis familiares preditoras do comportamento anti-social em adolescentes autores de atos infracionais. Psicologia: Teoria e Pesquisa, 25(2), 213219. https://doi.org/10.1590/ S0102-37722009000200009

Paravidini, J. L., \& Chaves, L. S. (2012). Atendimento psicanalítico conjunto pais-crianças: Uma investigação teórica, técnica e metodológica. Revista da SPAGESP, 13(2), 411. http://pepsic.bvsalud.org/pdf/rspagesp/v13n2/v13n2a02.pdf

Paulino, V. C. P., Rodrigues, J., Christóforo, B. E. B., Rodrigues, D. R., \& Silva, L. A. (2015). Rodas de conversa sobre a qualidade de vida no trabalho docente e a relação docente discente nos cursos de graduação e pós-graduação em saúde. Itinerarius Reflectionis, 11(1), 113. https://doi.org/10.5216/rir.v11i1.33165

Perfeito, H. (2007). Os impasses nas funções parentais: da clínica psicanalítica do precoce às transformações sócio-histórico-culturais [Dissertação de Mestrado, Universidade Federal de Uberlândia]. Programa de Pós-Graduação em Psicologia da Universidade Federal de Uberlândia. http://www.pgpsi.ip.ufu.br/node/234

Proposta de Emenda à Constituição no 171, de 1993. (1993). Altera a redação do art. 228 da Constituição Federal (imputabilidade penal do maior de dezesseis anos). https://www.camara.leg.br/proposicoesWeb/ fichadetramitacao?idProposicao $=14493 \&$ mobile \&width $=28007$

Proposta de Emenda à Constituição no 33 de 2012. (2012). Altera a redação dos arts. 129 e 228 da Constituição Federal, acrescentando um parágrafo único para prever a possibilidade de desconsideração da inimputabilidade penal de maiores de dezesseis anos e menores de dezoito anos por lei complementar. https://www25.senado.leg.br/web/ atividade/materias/-/materia/106330

Real, F. G., \& Conceição, M. I. (2013). Representações sociais de parlamentares brasileiros sobre a redução da maioridade penal. Psicologia Ciência e Profissão, 33(3), 656671. https://doi.org/10.1590/s1414-98932013000300011

Secretaria de Estado de Educação de Minas Gerais. (2016). Resolução do Estado de Minas Gerais no 2.957, de 20 de abril de 2016. Dispõe sobre a implantação do projeto "Elevação da Escolaridade - Metodologia Telessala Minas Gerais" para os estudantes dos anos finais da rede estadual de ensino. https://www2.educacao.mg.gov.br/images/ documentos/2957-16-r.pdf

Rizzini, I., \& Pilotti, F. (2009). A arte de governar crianças: A história das políticas sociais, da legislação e da assistência à infância no Brasil (2a ed.). Cortez. 
Psicologia: Ciência e Profissão 2021 v. 41 (n.spe 4), e217551,1-17.

Rocha, Z. (1999). Desamparo e metapsicologia - para situar o conceito de desamparo no contexto da metapsicologia freudiana. Sintese, 26(86), 331346. http://www.faje.edu.br/periodicos/index.php/Sintese/article/view/761/1194

Rosa, M. D., \& Domingues, E. (2010). O método na pesquisa psicanalítica de fenômenos sociais e políticos: A utilização da entrevista e da observação. Psicologia \& Sociedade, 22(1), 180188. https://doi.org/10.1590/ S0102-71822010000100021

Rosa, M. D., \& Vicentin, M. C. (2010). Os intratáveis: O exílio do adolescente do laço social pelas noções de periculosidade e irrecuperalidade. Revista Psicologia Política, 10(19), 107124. http://pepsic.bvsalud.org/pdf/rpp/ v10n19/v10n19a10.pdf

Saggese, E., \& Leite, L. C. (2011). Da clínica à reabilitação social: Manual de saúde mental de crianças e adolescentes. Cadernos Ipub.

Sampaio, J., Santos, G. C., Agostini, M., \& Salvador, A. S. (2014). Limites e potencialidades das rodas de conversa no cuidado em saúde: Uma experiência com jovens no sertão pernambucano. Interface: Comunicação, Saúde, Educação, 18(Suppl. 2), 12991311. https://doi.org/10.1590/1807-57622013.0264

Sawaia, B. (2001). As artimanhas da exclusão: Análise psicossocial e ética da desigualdade social (3a ed.). Vozes.

Schneider, J. A., Mello, L. T. N., Limberger, J., \& Andretta, I. (2016). Adolescentes usuários de drogas e em conflito com a lei: revisão sistemática da literatura nacional. Psicologia Argumento, 34(85), 120132. http:// doi.org/10.7213/psicol.argum.34.085.AO03

Vaz, B. G., \& Moreira, J. S. S. (2015). Responsabilização x Responsabilidades: O adolescente autor de ato infracional e a redução da maioridade penal. Psicologia Argumento, 33(82), 346363. http://doi.org/10.7213/ psicol.argum.33.082.AO02

Voltolini, R. (2005). A inclusão é não toda. In F. Coli, \& M. Kupfer (Orgs.), Travessias inclusão escolar: A experiência do grupo ponte - pré-escola terapêutica lugar de vida (pp. 149-156). Casa do Psicólogo.

\section{Michelle Ferreira Martins}

Psicóloga e mestre em Psicologia na linha de Psicanálise e Cultura pela Universidade Federal de Uberlândia (UFU), Uberlândia - MG. Brasil.

E-mail: michellefmartins@yahoo.com.br

(1) https://orcid.org/0000-0002-2549-4022

\section{Maíra Lopes Almeida}

Psicóloga e mestre em Psicologia na linha de Psicanálise e Cultura pela Universidade Federal de Uberlândia (UFU), Uberlândia - MG. Brasil.

E-mail: maira.lpalmeida@gmail.com

(1) https://orcid.org/ 0000-0002-6956-9858

\section{Tassiana Machado Quagliatto}

Psicóloga e mestre em Psicologia na linha de Psicanálise e Cultura pela Universidade Federal de Uberlândia (UFU), Uberlândia - MG. Brasil.

E-mail: tassianaquagliatto@hotmail.com

(1) https://orcid.org/0000-0003-2006-0425

\section{Artur Júlio de Albuquerque Junior}

Psicólogo e mestre em Psicologia na linha de Psicanálise e Cultura pela Universidade Federal de Uberlândia (UFU), Uberlândia - MG. Brasil.

E-mail: artur26junior@gmail.com

(1) https://orcid.org/0000-0001-5992-2251 


\section{Rita de Cássia Cardoso da Silva Mendes}

Psicóloga e mestre em Psicologia na linha de Psicanálise e Cultura pela Universidade Federal de Uberlândia (UFU), Uberlândia - MG. Brasil.

E-mail: rita_silva_mendes@yahoo.com.br

(D) https://orcid.org/0000-0002-6314-2837

\section{João Luiz Leitão Paravidini}

Doutor em Ciências Médicas pela Universidade Estadual de Campinas (Unicamp) e Professor associado da Universidade Federal de Uberlândia (UFU), Uberlândia - MG. Brasil.

E-mail: jlparavidini@gmail.com.

(D) https://orcid.org/0000-0002-2685-3808

Agradecimentos e fonte de financiamento:

Agradecemos à Coordenação de Aperfeiçoamento de Pessoal de Nível Superior (CAPES), que ofereceu apoio financeiro por meio de bolsas de mestrado aos quatro primeiros autores. Agradecemos também à Fundação de Amparo à Pesquisa de Minas Gerais (FAPEMIG) pelo auxílio financeiro concedido por meio de bolsa de mestrado para a quinta autora.

Endereço para envio de correspondência:

Instituto de Psicologia. Av. Pará, 1720, bloco 2C, Campus Umuarama. CEP: 38405-320. Uberlândia - MG. Brasil.

Recebido $10 / 12 / 2018$

Aceito 18/05/2020

Received $12 / 10 / 2018$

Approved 05/18/2020

Recibido 10/12/2018

Aceptado 18/05/2020

Como citar: Martins, M. F., Almeida, M. L., Quagliatto, T. M., Albuquerque, A. J., Jr., Mendes, R. C. C. S., \& Paravidini, J. L. (2021). A Redução da Idade de Responsabilidade Criminal na Perspectiva de Adolescentes. Psicologia: Ciência e Profissão, 41 (n.spe 4), 1-17. https://doi.org/10.1590/1982-3703003217551

How to cite: Martins, M. F., Almeida, M. L., Quagliatto, T. M., Albuquerque, A. J., Jr., Mendes, R. C. C. S., \& Paravidini, J. L. (2021). Lowering the Minimum Age of Criminal Responsibility from the Perspective of Adolescents. Psicologia: Ciência e Profissão, 41 (n.spe 4), 1-17. https://doi.org/10.1590/1982-3703003217551

Cómo citar: Martins, M. F., Almeida, M. L., Quagliatto, T. M., Albuquerque, A. J., Jr., Mendes, R. C. C. S., \& Paravidini, J. L. (2021). La Reducción de la Edad de Responsabilidad Penal desde la Perspectiva de Adolescentes. Psicologia: Ciência e Profissão, 41 (n.spe 4), 1-17. https://doi.org/10.1590/1982-3703003217551 